\title{
Muscle mass rather than muscle strength or physical performance is associated with metabolic syndrome in community- dwelling older Chinese adults
}

Peiyu Song ${ }^{1,2}$, Peipei Han ${ }^{1+}$, Yinjiao Zhao ${ }^{3+}$, Yuanyuan Zhang ${ }^{2}$, Liyan Wang ${ }^{2}$, Zhuoying Tao ${ }^{1}$, Zhengxing Jiang ${ }^{1}$, Shijing Shen ${ }^{1}$, Yunxiao $\mathrm{Wu}^{1}$, Jiajie $\mathrm{Wu}^{1}$, Xiaoyu Chen ${ }^{2}$, Xing Yu', Yong Zhao ${ }^{1}$ and Qi Guo ${ }^{1 *}$

\begin{abstract}
Objective: The purpose of this study was to examine whether muscle mass, muscle strength, and physical performance were associated with metabolic syndrome (MetS) in community-dwelling older Chinese adults.

Methods: The study comprised of 1413 community-dwelling Chinese participants (577 men; mean \pm standard deviation age: $71.3 \pm 5.9$ ) recruited from Tianjin and Shanghai, China who were invited to participate in a comprehensive geriatric assessment. The International Diabetes Federation metabolic syndrome guidelines were used to define MetS, including high waist circumference, elevated blood pressure, elevated fasting blood glucose, elevated triglycerides, and reduced HDL cholesterol. Muscle mass was measured by appendicular skeletal muscle mass/weight (ASM/weight), and ASM was measured by BIA. Muscle strength was measured using grip strength. Physical performance was represented by walking speed and the time up and go test (TUGT).

Results: The overall prevalence of MetS was $46.8 \%$ (34.1\% in males and 55.5\% in females). In the final logistic regression model, there was a significant, graded inverse association between muscle mass and MetS ( $\mathrm{p}$ for trend $=$ 0.014). Muscle strength and physical performance, including walking speed and TUGT, were not associated with overall MetS. In the components of MetS, muscle mass and grip strength were significantly inversely associated with high waist circumference and elevated blood pressure $(p<0.05)$, while physical performance was not associated with components of MetS.
\end{abstract}

Conclusions: Compared with muscle strength and muscle function, muscle mass was inversely associated with MetS in a community-dwelling elderly Chinese population. Among muscle mass, muscle strength and physical performance, muscle mass appears to have the strongest association with MetS in the elderly.

Keywords: Metabolic syndrome, Muscle mass, Muscle strength, Physical performance

\footnotetext{
* Correspondence: guoqijp@gmail.com

${ }^{\dagger}$ Peipei Han and Yinjiao Zhao contributed equally to this work and should be considered co-first author.

'Department of Rehabilitation Medicine, Shanghai University of Medicine and Health Sciences Affiliated Zhoupu Hospital, 1500 Zhouyuan Road, Pudong New District, Shanghai 201318, China

Full list of author information is available at the end of the article
}

(C) The Author(s). 2021 Open Access This article is licensed under a Creative Commons Attribution 4.0 International License, which permits use, sharing, adaptation, distribution and reproduction in any medium or format, as long as you give appropriate credit to the original author(s) and the source, provide a link to the Creative Commons licence, and indicate if changes were made. The images or other third party material in this article are included in the article's Creative Commons licence, unless indicated otherwise in a credit line to the material. If material is not included in the article's Creative Commons licence and your intended use is not permitted by statutory regulation or exceeds the permitted use, you will need to obtain permission directly from the copyright holder. To view a copy of this licence, visit http://creativecommons.org/licenses/by/4.0/ The Creative Commons Public Domain Dedication waiver (http://creativecommons.org/publicdomain/zero/1.0/) applies to the data made available in this article, unless otherwise stated in a credit line to the data. 


\section{Introduction}

Metabolic syndrome (MetS) is a cluster of cardiovascular risk factors, including central obesity, elevated blood pressure, elevated fasting blood glucose, and dyslipidemia. These factors have been proven to be significantly related to cardiovascular disease and all-cause mortality. Epidemiological evidence indicates that the incidence of MetS increases dramatically with age [1], and the risk of MetS in elderly people over 60 years old is $2-3$ times higher than that of adults [2, 3]. In China, aging is a severe challenge as the Chinese population over 60 years old reached 230 million in 2016. This number continues to increase, and is expected to be approximately 418 million by 2035 [4].

One of the most dramatic changes in the elderly aging process is the decline of muscle mass and function, As the main component of sarcopenia, it has been studied more and more [5]. Skeletal muscle is the main part of carbohydrate and fatty acid metabolism, and its endocrine function plays a key role in reversing metabolic disorder [6]. Muscle activity also complements skeletal muscle's adaptation in a multitude of signal pathways to maintain metabolic balance by enhancing glucose and lipid metabolism and endocrine activity [7]. Thus, skeletal muscle may play an important role in the development of MetS. Some studies have shown that low muscle mass is a risk factor for MetS [8], while others have found no such association [9]. Identifying the association between muscle characteristics and MetS may provide a new pathway for the treatment of MetS. Moreover, to the best of our knowledge, no studies have been performed on the relationship between muscle mass and MetS in the elderly Chinese population. Muscle function includes both muscle strength and physical performance [10]. Although the relationship between muscle strength and physical performance and MetS has been widely studied, no conclusive consensus on these associations has been reached [11-14]. It is worth noting that muscle strength has been proven to be an important biomarker of cardiovascular disease, cardiovascular death, and allcause death [15].

Therefore, the purpose of this study was to determine the association between muscle mass and function and MetS among community-dwelling elderly Chinese individuals, which account for about $70 \%$ of the elderly in China. In addition, the association between muscle mass and function and MetS was compared.

\section{Methods}

\section{Study participants}

The present study is a cross-sectional analysis, using data from Adult Physical Fitness and Health Cohort Study (APFHCS) [ChiCTR1900024880], APFHCS is a large prospective dynamic cohort study, mainly investigated the association between physical fitness and health status in a general adult population living in Tianjin and Shanghai, China. Participants were recruited for taking annual comprehensive health examinations and completed detailed questionnaires regarding their lifestyle and disease history. The data of this study were taken from August 2018 to July 2019. The survey is for comprehensively understanding the health testing indicators and evaluation systems of the elderly (age 60 and above). Prior to the survey, we explained the consent process, study procedures and purpose to the participant. The inclusion criteria were willingness to participate and cooperate with relevant inspections in the study. Exclusion criteria of this study were as follows: (1) age < 60 years; (2) unable to communicate with interviewers or to grant the informed consent; (3) history of condition, such as hand injury, which influences HS level; and (4) inability to stand upright for measurements of body composition, weight and height; (5) unable to perform the time up and go test or the 4-m walking test; (6) no blood samples were collected.

A total of 1506 people whom resides in Hangu District, Tianjin and Chongming District Shanghai, took part in the national free physical examination program as part of a comprehensive geriatric assessment. A flow chart detailing the derivation of sample is presented in Fig. 1. Due to missing values or criteria it was not possible to analyze 93 participants meaning 1413 are available for analyses. Our study was approved by the Ethics Committee of Tianjin Medical University and Shanghai University of Medicine and Health Sciences and its participants have provided informed consent prior to participation.

\section{Baseline variable}

All the participants were invited to a face-to-face interview to answer a standardized questionnaire after they completed their medical examination. The questionnaire included questions about age, sex, occupation, educational level, marital status (with spouse, widowed, unmarried, divorced), family income (<1000 yuan, 10003000 yuan, 3000-5000 yuan, $>5000$ yuan), smoking habits (current smoker or not), drinking habits (drinking alcohol once a week, drinking in the past, and never drinking were all considered as no drinking). Physical activity was assessed using the short form of the International Physical Activity Questionnaire (IPAQ) [16]. Nutritional status assessment using the Mini Nutritional Assessment-short form (MNA-SF) [17]. We also reviewed whether participants had chronic medical conditions, such as type 2 diabetes mellitus (T2DM), hypertension, hyperlipidemia, cardiovascular disease (CVD), stroke, kidney disease and cancer. 
Participants who received health examinations from the APFHCS cohort in 2018-2019( $\mathrm{n}=1506)$

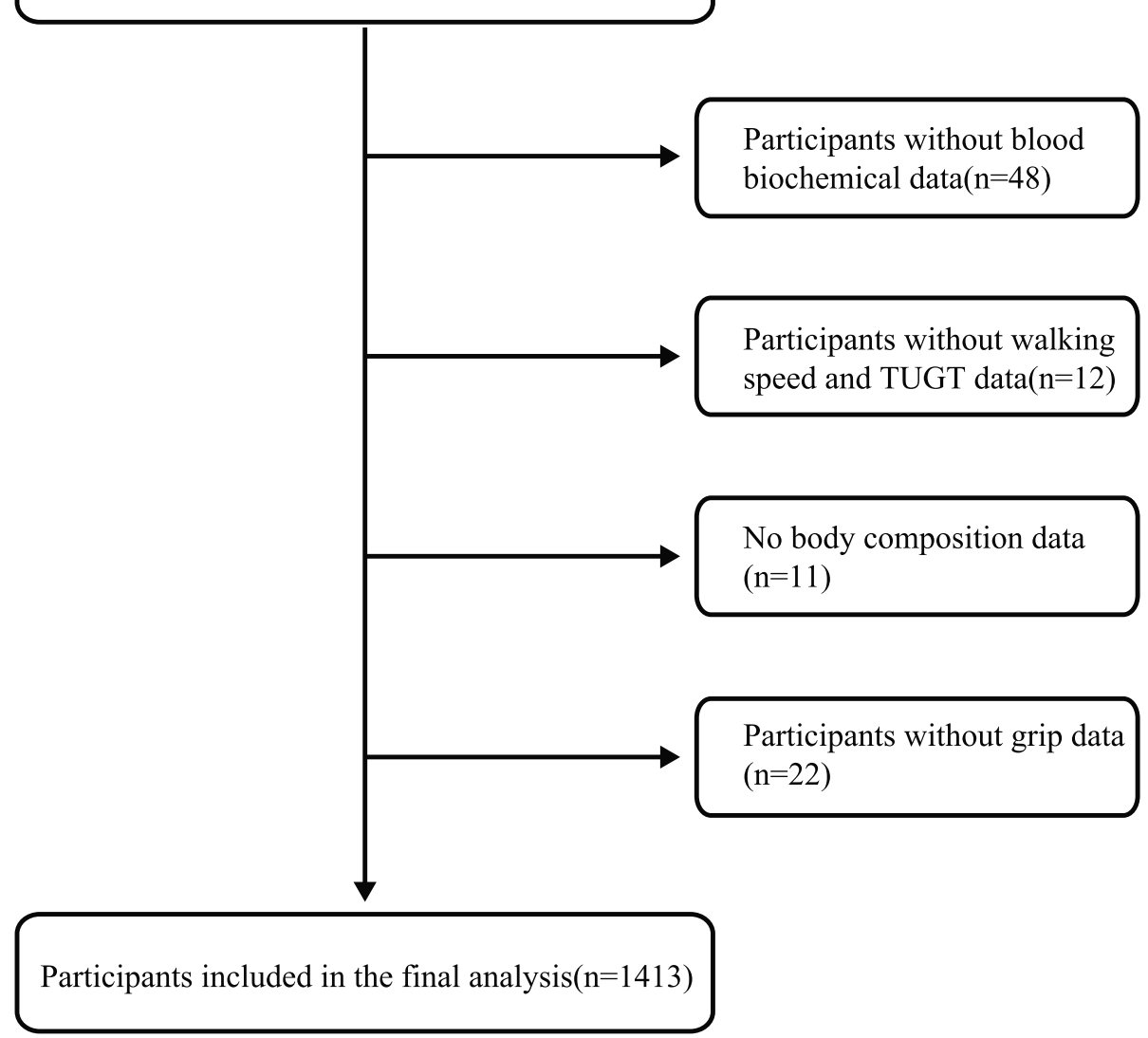

Fig. 1 Flowchart of the study population selection process

\section{Anthropometric measurements}

Bioimpedance analysis (In-Body720; Biospace Co., Ltd., Seoul, Korea) was used for estimating appendicular skeletal mass (ASM). The skeletal muscle mass index (SMI) was calculated as follows: SMI $(\%)=$ total ASM $(\mathrm{kg}) /$ body weight $(\mathrm{kg}) \times 100$ [18], which was modified from the study of Janssen et al. [19].

\section{Analysis of blood samples and blood pressure}

A blood sample was obtained from the antecubital vein from patients who fasted overnight for at least $10 \mathrm{~h}$. Blood sample analysis and blood pressure collection methods have been explained in our previous studies [20].

\section{Performance-based assessment}

Performance-based assessment consisted of several physical tests (4-m walking velocity test and the Timed Up and Go Test (TUGT)) and grip strength. Detailed test methods have been described in our previous studies [21].

\section{Definition of MetS}

According to the International Diabetes Federation (IDF), people with MetS are defined by having central obesity (WC $\geq 90 \mathrm{~cm}$ in men and $\geq 80 \mathrm{~cm}$ in women) along with two or more of the following abnormalities: (1) elevated triglycerides ( $\geq 150 \mathrm{mg} / \mathrm{dL})$; (2) reduced HDL cholesterol $(<40 \mathrm{mg} / \mathrm{dL}$ in men and $<50 \mathrm{mg} / \mathrm{dL}$ in women); (3) elevated blood pressure $(\geq 130 / 85 \mathrm{mmHg}$ or known treatment for hypertension); (4) elevated FPG ( $\geq 100 \mathrm{mg} / \mathrm{dL}$, or known treatment for diabetes) [22].

\section{Definition of sarcopenia}

Sarcopenia was defined according to the AWGS criteria [23], in which a person who has low muscle mass, low muscle strength, and/or low physical performance was identified as having sarcopenia. Low muscle mass was classified as a relative skeletal muscle mass index (ASM/ height $^{2}$ ) less than $7.0 \mathrm{~kg} / \mathrm{m}^{2}$ and $5.7 \mathrm{~kg} / \mathrm{m}^{2}$ in men and women, respectively; low muscle strength was defined as a grip strength $<26 \mathrm{~kg}$ or $<18 \mathrm{~kg}$ for males and females, respectively; low physical performance was defined as a walking speed $<0.8 \mathrm{~m} / \mathrm{s}$ for both males and females. 


\section{Statistical analysis}

All continuous variables were presented as means \pm SD; classification variables were reported as percentages. Differences in the characteristics according to metabolic syndrome status were analyzed using t-tests, chi-square test, and Kruskale Wallis rank tests. Participants were divided into four groups by quadrisection based on the results of grip strength/weight, ASM/weight, TUGT, and WS $[24,25]$. Logistic regression analysis was used to determine odds ratios (ORs) and 95\% CIs and to assess whether participants with MetS were independently associated with muscle mass muscle function and sarcopenia when compared with those without MetS. A linear trend across the quartiles of grip strength/weight, ASM/ weight, TUGT, and WS were tested by using the median value of each category as an ordinal variable. Linear regression was used for calculating $\mathrm{p}$ for trend in the logistic binary models [26]. Several confounding factors were adjusted: age, sex, educational level, family income, smoking status, occupation, physical activity level [24]. Differences were defined as significant when $p<0.05$. All statistical analyses were performed with the SPSS V22.0 software.

\section{Results}

\section{Baseline characteristics}

General characteristics of 1413 participants (577 men; mean age: $71.3 \pm 5.9)$ are given in Table 1 . The overall prevalence of MetS was $46.8 \%$ (34.1\% in males and $55.5 \%$ in females). Subjects with MetS had a higher percentage of high waist circumference, high blood pressure, elevated blood glucose, and dyslipidemia than subjects without MetS (all $p<0.01$ ). Moreover, subjects with MetS had significantly higher weight, BMI and incidence rate of CVD and stroke than those without MetS (all $\mathrm{p}<0.01$ ). However, subjects with MetS had significantly lower grip strength, SMI, and walking speed than subjects without MetS (all $\mathrm{p}<0.01$ ).

The association between muscle mass and muscle function and MetS is displayed in Table 2. The results showed that the elderly with lower grip strength, slower walking speed and lower SMI were more likely to suffer from MetS in the unadjusted population. In the final logistic models, subjects in the lower quartile for SMI had a significantly higher risk for MetS compared with those in the fourth quartile and were as follows: 0.67 (0.45$1.00) ; 0.27$ (0.15-0.47); and $0.04(0.01-0.14)$ ( $\mathrm{p}$ for trend $<0.05$ ).

The association between muscle mass and muscle function and MetS is displayed in Table 3. After adjustment, there was no significant association between sarcopenia and metabolic syndrome and its components.

The relationship between SMI, grip strength, walking speed, TUGT and the components of MetS is shown in
Table 1 General Characteristics of participants with and without Mets

\begin{tabular}{|c|c|c|c|}
\hline Variable & MetS & Not MetS & $\mathbf{P}$ \\
\hline $\mathrm{N}$ & 662 & 752 & \\
\hline Age(y) & $71.4 \pm 6.0$ & $71.1 \pm 6.0$ & 0.365 \\
\hline Sex & & & $<0.001$ \\
\hline Male(\%) & 29.8 & 50.5 & \\
\hline Female(\%) & 70.2 & 49.5 & \\
\hline Weight(kg) & $64.8 \pm 10.8$ & $59.2 \pm 11.0$ & $<0.001$ \\
\hline $\mathrm{BMI}\left(\mathrm{kg} / \mathrm{m}^{2}\right)$ & $25.6 \pm 3.1$ & $22.8 \pm 3.3$ & $<0.001$ \\
\hline Illiteracy (\%) & 20.1 & 17.2 & 0.152 \\
\hline Farming (\%) & 59.8 & 54.5 & 0.047 \\
\hline Smoking (\%) & 12.1 & 22.9 & $<0.001$ \\
\hline Drinking (\%) & 22.0 & 31.7 & $<0.001$ \\
\hline Grip(kg) & $23.7 \pm 8.8$ & 21.6 & $<0.001$ \\
\hline Grip/weight (\%) & $33.3 \pm 12.0$ & $40.3 \pm 13.7$ & $<0.001$ \\
\hline $\mathrm{ASM}(\mathrm{kg})$ & $17.9 \pm 4.5$ & $17.6 \pm 4.4$ & 0.184 \\
\hline SMI(\%) & $27.0 \pm 4.2$ & $30.1 \pm 5.1$ & $<0.001$ \\
\hline IPAQ(Met/wk) & $5654 \pm 6622$ & $6177 \pm 6665$ & 0.053 \\
\hline TUGT(s) & $10.6 \pm 4.0$ & $10.2 \pm 7.1$ & 0.616 \\
\hline WS(m/s) & $1.04 \pm 0.24$ & $1.09 \pm 0.24$ & $<0.001$ \\
\hline MNA & $11.2 \pm 1.3$ & $11.2 \pm 1.2$ & 0.639 \\
\hline \multicolumn{4}{|l|}{ MetS components (\%) } \\
\hline High WC & 100 & 48.5 & $<0.001$ \\
\hline Elevated blood pressure & 90.2 & 57 & $<0.001$ \\
\hline Elevated fasting glucose & 67.9 & 28.2 & $<0.001$ \\
\hline Elevated TG & 61.6 & 17.6 & $<0.001$ \\
\hline Low HDL & 36.6 & 6.9 & $<0.001$ \\
\hline \multicolumn{4}{|l|}{ Chronic conditions (\%) } \\
\hline CVD & 34.5 & 26.9 & 0.002 \\
\hline Stroke & 26 & 18.4 & 0.001 \\
\hline Cancer & 2.1 & 2.7 & 0.507 \\
\hline Kidney disease & 8.5 & 8.0 & 0.736 \\
\hline
\end{tabular}

Notes: BMI, body mass index; ASM, appendicular skeletal mass; SMI, skeletal muscle mass index; TUGT, timed up and go test; WS, $4 \mathrm{~m}$ walking speed; MNA, Mini-Nutritional Assessment; IPAQ, International Physical Activity

Questionnaire; WC, waist circumference; MetS, metabolic syndrome. Data are presented as mean $\pm \mathrm{SD}$ or $\mathrm{n}(\%)$

Table 4. In the adjusted logistic regression model, both lower muscle mass and lower grip strength were significantly associated with an increased risk of high waist circumference and elevated blood pressure $(p<0.05)$, but not with other components. Walking speed and TUGT were not associated with MetS components.

\section{Discussion}

The purpose of this cross-sectional study was to examine the relationship between muscle mass and function and MetS in a community-dwelling elderly Chinese 
Table 2 Logistic regression analyses of the association of grip, SMI, TUGT, and walking speed quartiles with MetS

\begin{tabular}{|c|c|c|c|c|c|}
\hline & Q1 & Q2 & Q3 & Q4 & $P$ for trend \\
\hline \multicolumn{6}{|l|}{ Grip/weight(\%) } \\
\hline$N$ & 353 & 353 & 354 & 353 & \\
\hline Crude & Ref & $0.88(0.65-1.19)$ & $0.55(0.41-0.75)$ & $0.23(0.17-0.32)$ & 0.012 \\
\hline Adjusted model & Ref & $0.98(0.63-1.52)$ & $0.40(0.25-0.64)$ & $0.37(0.21-0.65)$ & 0.106 \\
\hline \multicolumn{6}{|l|}{ SMI (\%) } \\
\hline$N$ & 350 & 354 & 354 & 385 & \\
\hline Crude & Ref & $0.68(0.50-0.93)$ & $0.48(0.36-0.66)$ & $0.12(0.09-0.18)$ & 0.009 \\
\hline Adjusted model & Ref & $0.67(0.45-1.00)$ & $0.27(0.15-0.47)$ & $0.04(0.01-0.14)$ & 0.014 \\
\hline \multicolumn{6}{|l|}{ WS (m/s) } \\
\hline$N$ & 352 & 354 & 354 & 353 & \\
\hline Crude & Ref & $0.80(0.59-1.07)$ & $0.73(0.54-0.98)$ & $0.59(0.43-0.79)$ & 0.004 \\
\hline Adjusted model & Ref & $0.71(0.44-1.15)$ & $0.75(0.45-1.24)$ & $0.71(0.42-1.21)$ & 0.181 \\
\hline \multicolumn{6}{|l|}{ TUGT (s) } \\
\hline$N$ & 353 & 354 & 354 & 352 & \\
\hline Crude & Ref & $1.60(1.18-2.16)$ & $1.34(0.99-1.81)$ & $1.66(1.23-2.25)$ & 0.270 \\
\hline Adjusted model & Ref & $1.42(0.85-2.37)$ & $1.13(0.67-1.89)$ & $1.09(0.64-1.87)$ & 0.247 \\
\hline
\end{tabular}

Data are presented as adjusted $\mathrm{OR}$, with $95 \% \mathrm{Cl}$ in parentheses, unless otherwise stated

Adjusted model is adjusted with age, sex, smoking status, drinking, occupation, MNA, educational level, family income and physical activity level, CHD, stroke Notes: SMI skeletal muscle mass index, TUGT timed up and go test, WS $4 \mathrm{~m}$ walking speed, MNA Mini-Nutritional Assessment, MetS metabolic syndrome,

$Q$ quartiles

population. A significant, graded inverse association between muscle mass and the risk of MetS was observed. However, although muscle strength was inversely associated with high waist circumference and high blood pressure, it was not grade inversely associated with overall MetS, and there was no association between physical performance and MetS or its components.

In previous studies, the relationship between muscle mass and MetS has not been fully established. Several studies have shown that low muscle mass is a risk factor for MetS [8, 27]; however, there are contradictions within these results. A Korean cross-sectional study of subjects over 70 years old showed that low relative muscle mass is not an independent risk factor for MetS as the association fell away after combining with central obesity [9]. Similarly, another study showed that low muscle mass was a risk factor for MetS in the non-obese elderly but not in the obese elderly [28]. Our results are consistent with these previous studies. Low muscle mass was a risk factor for MetS in non-obese communitydwelling elderly Chinese people ( $p$ for trend $=0.009$ ), while this risk factor was not significant in obese people, see supplementary Table 2 . In contradiction, studies have shown that the obese group with normal muscle mass has the highest risk of MetS among four groups stratified by obesity and low muscle mass [29]. Two reasons for the discrepancies in results from these studies may exist: first, in the overweight and obese elderly,

Table 3 Logistic regression analyses of the association of sarcopenia with MetS and its components

\begin{tabular}{lllll}
\hline Variable & \multicolumn{1}{l}{ Odds ratio(95\%Cl) } & & \\
\cline { 2 - 4 } & \multicolumn{1}{c}{ Crude } & $\mathbf{P}$ & Adjusted model \\
\hline Sarcopenia & & & & P \\
Metabolic syndrome & $0.48(0.34-0.68)$ & $<0.001$ & $1.08(0.70-1.66)$ & 0.726 \\
High waist circumference & $0.24(0.17-0.33)$ & $<0.001$ & $1.20(0.58-2.48)$ & 0.630 \\
Elevated blood pressure & $0.74(0.52-1.05)$ & 0.094 & $1.08(0.64-1.84)$ & 0.767 \\
Elevated fasting glucose & $1.04(0.75-1.45)$ & 0.796 & $1.39(0.87-2.23)$ & 0.170 \\
Elevated TG & $0.76(0.54-1.08)$ & 0.126 & $1.07(0.64-1.77)$ & 0.805 \\
Low HDL & $1.13(0.76-1.67)$ & 0.556 & $1,67(0.95-2.94)$ & 0.077 \\
\hline
\end{tabular}

Data are presented as adjusted $\mathrm{OR}$, with $95 \% \mathrm{Cl}$ in parentheses, unless otherwise stated

Adjusted model is adjusted with age, sex, BMl, smoking status, drinking, occupation, MNA, educational level, family income and physical activity level, CHD, stroke Notes: MNA Mini-Nutritional Assessment, MetS metabolic syndrome 
Table 4 Logistic regression analyses of the association of grip, SMI and walking speed with MetS components

\begin{tabular}{|c|c|c|c|c|c|}
\hline \multirow[t]{2}{*}{ Variable } & \multicolumn{5}{|l|}{ Odds ratio( $95 \% \mathrm{Cl})$} \\
\hline & High waist circumference & Elevated blood pressure & Elevated fasting glucose & Elevated TG & Low HDL \\
\hline \multicolumn{6}{|l|}{ Grip/weight (\%) } \\
\hline Crude & $0.93(0.92-0.94)^{* *}$ & $0.98(0.97-0.99)^{* *}$ & $0.99(0.98-0.99) * *$ & $1.00(0.99-1.00)$ & $0.97(0.96-0.98) * *$ \\
\hline Adjusted model & $0.95(0.94-0.97)^{* *}$ & $0.98(0.96-0.99)^{* *}$ & $1.00(0.98-1.01)$ & $1.00(0.99-1.02)$ & $1.00(0.98-1.02)$ \\
\hline \multicolumn{6}{|l|}{ SMI (\%) } \\
\hline Crude & $0.73(0.70-0.76) * *$ & $0.95(0.93-0.98)^{* *}$ & $0.97(0.95-0.99)^{* *}$ & $0.98(0.96-1.00)$ & $0.88(0.85-0.91)^{* *}$ \\
\hline Adjusted model & $0.56(0.49-0.63)^{* *}$ & $0.99(0.82-0.94)^{* *}$ & $1.01(0.96-1.06)$ & $0.97(0.92-1.03)$ & $0.97(0.92-1.04)$ \\
\hline \multicolumn{6}{|l|}{ WS (m/s) } \\
\hline Crude & $0.51(0.31-0.85)^{* *}$ & $0.43\left(0.26-0.71^{* *}\right.$ & $0.58(0.37-0.90) *$ & $0.96(0.61-1.50)$ & $0.51(0.30-0.87) *$ \\
\hline Adjusted model & $0.84(0.35-2.00)$ & $0.83(0.37-1.88)$ & $0.62(0.31-1.24)$ & $1.33(0.63-2.81)$ & $0.62(0.26-1.49)$ \\
\hline \multicolumn{6}{|l|}{ TUGT (s) } \\
\hline Crude & $1.04(1.00-1.08) *$ & $1.01(0.98-1.04)$ & $1.01(0.99-1.03)$ & $0.98(0.95-1.01)$ & $1.01(0.99-1.03)$ \\
\hline Adjusted model & 1.05(1.00-1.11) & $0.98(0.96-1.00)$ & $1.00(0.98-1.02)$ & $0.98(0.94-1.02)$ & $1,00(0.97-1.02)$ \\
\hline
\end{tabular}

Data are presented as adjusted OR, with $95 \% \mathrm{Cl}$ in parentheses, unless otherwise stated, ${ }^{*} p<0.05,{ }^{* *} p<0.01$

Adjusted model is adjusted with age, sex, smoking status, drinking, occupation, MNA, educational level, family income and physical activity level, CHD, stroke

Notes: SMI skeletal muscle mass index, TUGT timed up and go test, WS $4 \mathrm{~m}$ walking speed, MNA Mini-Nutritional Assessment, MetS metabolic syndrome

there may be different cut-off point values for low muscle mass; second, the methods to define muscle mass indices may cause inconsistency. At present, the main definition of muscle mass is ASM adjusted by the weight or square of height. In our study, we used weight adjusted ASM as it has been shown to be more closely related to MetS and its parameters than ASM/height ${ }^{2}$ [30], and a stronger association between weight adjusted ASM and MetS has been reported [8, 27]. Adjusting for height does not take body fat into account, while weight includes both muscle and fat mass. Thus, it is not clear whether low muscle mass defined by ASM/weight represents relatively low muscle mass, relatively rich fat mass, or both. More precise adjustment may help to more clearly elucidate the relationship between muscle mass and MetS rather than increasing the diagnostic sensitivity. The ratio of muscle mass to visceral fat has been shown to be an important predictor of MetS [31]. Taken altogether, the relationship between muscle mass and MetS needs further study in the future.

As surrogate of muscle strength, grip strength is a proven risk stratification method for all-cause death, cardiovascular death, and cardiovascular disease [32]. Although the relationship between muscle strength and MetS has been proven by many studies, the conclusion has not reached a consensus. A Taiwanese study showed that there was no association between absolute grip strength and MetS [12], but there was a association between grip strength and MetS after weight adjustment [33]. Recently, the Foundation for the National Institutes of Health sarcopenia project has suggested that grip strength corrected by body mass index is a good marker for incident adverse health outcomes [34]. Another study also showed that grip strength/body fat mass appears to be the index best associated with MetS [22]. Our study reaffirmed these findings with a significant, graded inverse association between grip strength/body fat mass and MetS ( $p$ for trend $=0.045$ ). Future studies need to further identify grip strength indexes that are more relevant to MetS. Although our results suggest that greater muscle strength is a protective factor for MetS, there was no significant difference in overall trend. Muscle strength declines more rapidly during aging than the associated decline in muscle mass [35]. Additionally, the muscle strength and mass of elderly men decreases gradually before the age of 75 , and then shows a sharp decline after 75 years old [10]. With an average age $71.3 \pm 5.9$ years, our population falls in this transition period of sharp decline in muscle strength, which may partly explain our observed nonlinear association between muscle strength and the risk of MetS.

As one of the components of muscle function, physical performance involves the interaction among nerves, balance, and muscle groups. Previous investigations of the relationship between MetS and a variety of physical performance measurements have focused on the general population of older adults, with mixed results. While studies have found that slower walking speed and poor dynamic balance are risk factors for MetS [36, 37], others have not found this association $[14,38]$. Sample size issues and the selection of special population (e.g. high-risk population of mobility disability) may have contributed to these differences in results. In our study, there was no significant association between physical performance assessed by walking speed and TUGT and the risk of MetS. Our participants had good functional 
ability, which may underestimate the risk of MetS in this population. Physical performance is affected by many factors, such as the decline of muscle mass and muscle strength [39], such that it may be the result of MetS rather than the cause. As a multi-system coordination unit, a multitude of components involved in physical performance need to be impaired before it translates to poor overall physical performance. Therefore, redundancy may exist [40].

There is no significant difference between sarcopenia and metabolic syndrome, which may be due to the lack of significant association between the indicators in the current diagnostic criteria of sarcopenia and metabolic syndrome. ASM $/ \mathrm{ht}^{2}$ provided significant associations with physical disability or frailty, however, because this index is positively correlated with BMI, it has the limitation that subjects with a greater BMI due to a larger amount of fat are less likely to be classified as having sarcopenia [41]. Therefore, its confounding effect may obscure the association with metabolic syndrome.

The significant association between muscle mass and MetS may be explained by a few reasons. First, the plasma glucose uptake stimulated by insulin mainly occurs in skeletal muscle, which highlights its importance in blood glucose control [42]. Second, if the ability of lipid oxidation of skeletal muscle is impaired, it will cause ectopic fat accumulation and may reduce insulin action by interference with insulin signaling [43]. Third, myokine secreted by skeletal muscle fibers, such as IL-6 [44] and irisin [45], has a strong biological effect on reversing metabolic disorder, and the decrease of skeletal muscle mass also causes the decrease of endocrine function.

This study had a few limitations. All participants in the present study were relatively healthy as we did not include participants who were unable to participate in the free annual national physical examination (e.g. those bedridden or with serious disease). Due to this, our results might in fact underestimate of the prevalence of MetS and its associated health impact. Additionally, BIA is not a gold standard for measuring body composition, and its measurement results may not be as accurate as DXA.

In conclusion, our study found that there was a significant, grade inverse association between muscle mass and MetS in a community-dwelling elderly Chinese population. Although higher muscle strength was associated with a lower risk of MetS, it was not linear, and physical performance was not associated with MetS. These results suggest the use of muscle mass improvement training to prevent MetS. The underlying mechanism behind this relationship is still unclear, and future research needs to determine its mechanisms and its ability to predict MetS.

\section{Supplementary Information}

The online version contains supplementary material available at https://doi. org/10.1186/s12877-021-02143-8.

Additional file 1 : Supplementary Table 1. Logistic regression analyses of the association of grip and ALM quartiles with MetS. Supplementary Table $\mathbf{2}$. Logistic regression analyses of the association of SMI quartiles with MetS in obese and non- obese population.

\section{Acknowledgments}

The authors thank Guiyan Shao from the Chadian public health center, Xiaofang Ren from Hangu welfare house for providing place and organization and Xiaoyue Gu from the Chongming public health center for providing place and organization.

\section{Conflict of interest}

The authors declare that they have no competing interests.

\section{Authors' contributions}

Study concept and design: Q G, Py S. Acquisition of data: Yy Z, Zy T, Zx J, Sj $S, Y x W$, Jj W, Xy C, X Y, Y Z, Ly W. Drafting of the manuscript: Py S, Pp H. Critical revision of the manuscript for important intellectual content: Py S, Pp H, Yj Z, Q G. The author(s) read and approved the final manuscript.

\section{Funding}

This work was supported by the funding of Youth Fund Project of Research Planning Foundation on Humanities and Social Sciences of the Ministry of Education (20YJCZH001); Shanghai Sailing Program(20YF1418200).

\section{Availability of data and materials}

The processed data required to reproduce these findings cannot be shared at this time as the data also forms part of an ongoing study, however, it can be obtained from the corresponding author of this article on reasonable request.

\section{Declarations}

\section{Ethics approval and consent to participate}

This research was approved by the Ethics Committee at Tianjin Medical University and Shanghai University of Medicine and Health Sciences. The methodological sessions were carried out in accordance with the approved guidelines and regulations. The participants were fully informed of the nature of research and signed an informed consent to participate.

Consent for publication

All authors have read and approved the submission of the manuscript.

\section{Competing interests}

The authors declare that they have no competing interests.

\section{Author details}

${ }^{1}$ Department of Rehabilitation Medicine, Shanghai University of Medicine and Health Sciences Affiliated Zhoupu Hospital, 1500 Zhouyuan Road, Pudong New District, Shanghai 201318, China. ${ }^{2}$ Department of Rehabilitation Medicine, Tianjin Medical University, Tianjin, China. ${ }^{3}$ Tianjin Key Laboratory of Metabolic Cardiovascular Diseases, Key Laboratory of Immune

Microenvironment and Disease-Ministry of Education, Department of Physiology and Pathophysiology, Tianjin Medical University, Tianjin, China.

Received: 1 December 2020 Accepted: 8 March 2021

Published online: 19 March 2021

References

1. Dominguez $\sqcup$, Barbagallo M. The biology of the metabolic syndrome and aging. Curr Opinion Clin Nutri Metabol Care. 2016;19(1):5-11. https://doi. org/10.1097/MCO.0000000000000243

2. Lu J, Wang L, Li M, Xu Y, Jiang Y, Wang W, Li J, Mi S, Zhang M, Li Y, Wang T, Xu M, Zhao Z, Dai M, Lai S, Zhao W, Wang L, Bi Y, Ning G, 2010 China Noncommunicable Disease Surveillance Group. Metabolic syndrome among adults in China: the 2010 China noncommunicable disease surveillance. J 
Clin Endocrinol Metab. 2017;102(2):507-15. https://doi.org/10.1210/jc.201 6-2477.

3. Aguilar M, Bhuket T, Torres S, Liu B, Wong RJ. Prevalence of the metabolic syndrome in the United States, 2003-2012. Jama. 2015;313(19):1973-4. https://doi.org/10.1001/jama.2015.4260.

4. Li X, Fan L, Leng SX. The aging tsunami and senior healthcare development in China. J Am Geriatr Soc. 2018;66(8):1462-8. https://doi.org/10.1111/jgs.1 5424.

5. Larsson L, Degens H, Li M, Salviati L, Lee Yl, Thompson W, Kirkland JL, Sandri M. Sarcopenia: aging-related loss of muscle mass and function. Physiol Rev. 2019;99(1):427-511. https://doi.org/10.1152/physrev.00061.2017.

6. Zhang H, Lin S, Gao T, Zhong F, Cai J, Sun Y, Ma A. Association between Sarcopenia and Metabolic Syndrome in Middle-Aged and Older Non-Obese Adults: A Systematic Review and Meta-Analysis. Nutrients. 2018;10(3):364.

7. Myers J, Kokkinos P, Nyelin E. Physical Activity, Cardiorespiratory Fitness, and the Metabolic Syndrome. Nutrients. 2019;11(7):1652.

8. Kim G, Lee SE, Jun JE, Lee YB, Ahn J, Bae JC, Jin SM, Hur KY, Jee JH, Lee MK, Kim JH. Increase in relative skeletal muscle mass over time and its inverse association with metabolic syndrome development: a 7-year retrospective cohort study. Cardiovasc Diabetol. 2018;17(1):23. https://doi.org/10.1186/s12 933-018-0659-2.

9. Koo HS, Kim MJ, Kim KM, Kim YS. Decreased muscle mass is not an independent risk factor for metabolic syndrome in Korean population aged 70 or older. Clin Endocrinol. 2015;82(4):509-16. https://doi.org/10.1111/ cen.12509.

10. Cruz-Jentoft AJ, Sayer AA. Sarcopenia. Lancet (London, England). 2019; 393(10191):2636-46.

11. Yang EJ, Lim S, Lim JY, Kim KW, Jang HC, Paik NJ. Association between muscle strength and metabolic syndrome in older Korean men and women: the Korean longitudinal study on health and aging. Metab Clin Exp. 2012;61 (3):317-24. https://doi.org/10.1016/j.metabol.2011.07.005.

12. Chang KV, Hung CY, Li CM, Lin YH, Wang TG, Tsai KS, Han DS. Reduced flexibility associated with metabolic syndrome in community-dwelling elders. PLoS One. 2015;10(1):e0117167. https://doi.org/10.1371/journal.pone. 0117167.

13. Everson-Rose SA, Paudel M, Taylor BC, Dam T, Cawthon PM, Leblanc E, Strotmeyer ES, Cauley JA, Stefanick ML, Barrett-Connor E, et al. Metabolic syndrome and physical performance in elderly men: the osteoporotic fractures in men study. J Am Geriatr Soc. 2011;59(8):1376-84. https://doi. org/10.1111/j.1532-5415.2011.03518.x.

14. Botoseneanu A, Ambrosius WT, Beavers DP, de Rekeneire N, Anton S, Church T, Folta SC, Goodpaster BH, King AC, Nicklas BJ, Spring B, Wang X, Gill TM, the LIFE Study Groups. Prevalence of metabolic syndrome and its association with physical capacity, disability, and self-rated health in lifestyle interventions and Independence for elders study participants. J Am Geriatr Soc. 2015;63(2):222-32. https://doi.org/10.1111/jgs.13205.

15. Sayer AA, Kirkwood TB. Grip strength and mortality: a biomarker of ageing? Lancet (London, England). 2015;386(9990):226-7.

16. Craig $\mathrm{CL}$, Marshall AL, Sjöström M, Bauman AE, Booth ML, Ainsworth BE, Pratt M, Ekelund U, Yngve A, Sallis JF, et al. International physical activity questionnaire: 12-country reliability and validity. Med Sci Sports Exerc. 2003; 35(8):1381-95. https://doi.org/10.1249/01.MSS.0000078924.61453.FB.

17. Montejano Lozoya R, Martinez-Alzamora N, Clemente Marin G, Guirao-Goris SJA, Ferrer-Diego RM. Predictive ability of the mini nutritional assessment short form (MNA-SF) in a free-living elderly population: a cross-sectional study. PeerJ. 2017;5:e3345. https://doi.org/10.7717/peerj.3345.

18. Hong HC, Hwang SY, Choi HY, Yoo HJ, Seo JA, Kim SG, Kim NH, Baik SH, Choi DS, Choi KM. Relationship between sarcopenia and nonalcoholic fatty liver disease: the Korean Sarcopenic Obesity Study. Hepatology (Baltimore, Md). 2014;59(5):1772-8.

19. Janssen I, Heymsfield SB, Ross R. Low relative skeletal muscle mass (sarcopenia) in older persons is associated with functional impairment and physical disability. J Am Geriatr Soc. 2002;50(5):889-96. https://doi.org/10.1 046/j.1532-5415.2002.50216.x

20. Han P, Yu H, Ma Y, Kang L, Fu L, Jia L, Chen X, Yu X, Hou L, Wang L, Zhang W, Yin H, Niu K, Guo Q. The increased risk of sarcopenia in patients with cardiovascular risk factors in suburb-dwelling older Chinese using the AWGS definition. Sci Rep. 2017;7(1):9592. https://doi.org/10.1038/s41598-017-084888.

21. Fu L, Yu X, Zhang W, Han P, Kang L, Ma Y, Jia L, Yu H, Chen X, Hou L, Wang $L$, Guo $Q$. The relationship between sleep duration, falls, and muscle mass: a cohort study in an elderly Chinese population. Rejuvenation Res. 2019;22(5): 390-8. https://doi.org/10.1089/rej.2018.2102.

22. Song $P$, Zhang $Y$, Wang $Y$, Han $P$, Fu L, Chen $X$, Yu H, Hou L, Yu X, Wang L, Yang F, Guo Q. Clinical relevance of different handgrip strength indexes and metabolic syndrome in Chinese community-dwelling elderly individuals. Arch Gerontol Geriatr. 2020;87:104010. https://doi.org/10.1016/j.a rchger.2020.104010.

23. Chen LK, Liu LK, Woo J, Assantachai P, Auyeung TW, Bahyah KS, Chou MY, Chen LY, Hsu PS, Krairit O, Lee JSW, Lee WJ, Lee Y, Liang CK, Limpawattana P, Lin CS, Peng LN, Satake S, Suzuki T, Won CW, Wu CH, Wu SN, Zhang T, Zeng P, Akishita M, Arai H. Sarcopenia in Asia: consensus report of the Asian working Group for Sarcopenia. J Am Med Dir Assoc. 2014;15(2):95-101. https://doi.org/10.1016/j.jamda.2013.11.025.

24. Ma Y, Fu L, Jia L, Han P, Kang L, Yu H, Chen X, Yu X, Hou L, Wang L, et al. Muscle strength rather than muscle mass is associated with osteoporosis in older Chinese adults. Journal of the Formosan Medical Association = Taiwan yi zhi. 2018;117(2):101-8.

25. Yao Z, Gu Y, Zhang Q, Liu L, Meng G, Wu H, Xia Y, Bao X, Shi H, Sun S, Wang X, Zhou M, Jia Q, Wu Y, Song K, Gao W, Guo C, Niu K. Estimated daily quercetin intake and association with the prevalence of type 2 diabetes mellitus in Chinese adults. Eur J Nutr. 2019;58(2):819-30. https://doi.org/10.1 007/s00394-018-1713-2.

26. Gu Y, Li X, Zhang Q, Liu L, Meng G, Wu H, Zhang S, Wang Y, Zhang T, Wang X, Cao X, Li H, Liu Y, Sun S, Wang X, Jia Q, Song K, Sun Z, Niu K. Grip strength and depressive symptoms in a large-scale adult population: the TCLSIH cohort study. J Affect Disord. 2021;279:222-8. https://doi.org/10.101 6/j.jad.2020.08.023.

27. Kim JH, Park YS. Low muscle mass is associated with metabolic syndrome in Korean adolescents: the Korea National Health and nutrition examination survey 2009-2011. Nutrition research (New York, NY). 2016;36(12):1423-8.

28. Moon SS. Low skeletal muscle mass is associated with insulin resistance, diabetes, and metabolic syndrome in the Korean population: the Korea National Health and nutrition examination survey (KNHANES) 2009-2010. Endocr J. 2014;61(1):61-70. https://doi.org/10.1507/endocrj.EJ13-0244.

29. Baumgartner RN, Wayne SJ, Waters DL, Janssen I, Gallagher D, Morley JE. Sarcopenic obesity predicts instrumental activities of daily living disability in the elderly. Obes Res. 2004;12(12):1995-2004. https://doi.org/10.1038/oby.2 004.250.

30. Lim S, Kim JH, Yoon JW, Kang SM, Choi SH, Park YJ, Kim KW, Lim JY, Park KS, Jang HC. Sarcopenic obesity: prevalence and association with metabolic syndrome in the Korean longitudinal study on health and aging (KLoSHA). Diabetes Care. 2010;33(7):1652-4. https://doi.org/10.2337/dc10-0107.

31. Ramírez-Vélez R, Garcia-Hermoso A, Prieto-Benavides DH, Correa-Bautista JE, Quino-Ávila AC, Rubio-Barreto CM, González-Ruíz K, Carrillo HA, CorreaRodríguez $\mathrm{M}$, González-Jiménez $\mathrm{E}$, et al. Muscle mass to visceral fat ratio is an important predictor of the metabolic syndrome in college students. $\mathrm{Br}$ J Nutr. 2018;121(3):1-10.

32. Leong DP, Teo KK, Rangarajan S, Lopez-Jaramillo P, Avezum A Jr, Orlandini A, Seron P, Ahmed SH, Rosengren A, Kelishadi R, et al. Prognostic value of grip strength: findings from the Prospective Urban Rural Epidemiology (PURE) study. Lancet (London, England). 2015;386(9990):266-73.

33. Miyatake N, Saito T, Wada J, Nishikawa H, Matsumoto S, Miyachi M, Fujii M, Makino $\mathrm{H}$, Numata T. Linkage between oxygen uptake at ventilatory threshold and muscle strength in subjects with and without metabolic syndrome. Acta Med Okayama. 2007;61(5):255-9. https://doi.org/10.18926/A $\mathrm{MO} / 32895$.

34. Batsis JA, Germain CM, Vásquez E, Bartels SJ. Prevalence of weakness and its relationship with limitations based on the foundations for the National Institutes for health project: data from the health and retirement study. Eur J Clin Nutr. 2016;70(10):1168-73. https://doi.org/10.1038/ejcn.2016.90.

35. Delmonico MJ, Harris TB, Visser M, Park SW, Conroy MB, Velasquez-Mieyer P, Boudreau R, Manini TM, Nevitt M, Newman AB, et al. Longitudinal study of muscle strength, quality, and adipose tissue infiltration. Am J Clin Nutr. 2009;90(6):1579-85.

36. Vieira DC, Tibana RA, Tajra V, Nascimento Dda C, de Farias DL, Silva Ade O, Teixeira TG, Fonseca RM, de Oliveira RJ, Mendes FA, Martins WR, Funghetto SS, Karnikowski MG, Navalta JW, Prestes J. Decreased functional capacity and muscle strength in elderly women with metabolic syndrome. Clin Interv Aging. 2013;8:1377-86. https://doi.org/10.2147/CIA.S50333.

37. Beavers KM, Hsu FC, Houston DK, Beavers DP, Harris TB, Hue TF, Kim L, Koster A, Penninx BW, Simonsick EM, Strotmeyer ES, Kritchevsky SB, Nicklas 
BJ, Health ABC Study. The role of metabolic syndrome, adiposity, and inflammation in physical performance in the health $A B C$ study. J Gerontol A Biol Sci Med Sci. 2013;68(5):617-23. https://doi.org/10.1093/gerona/gls213.

38. Gottlieb MG, Closs VE, Rosemberg LS, Borges CA, Baptista RR, Tavares GM, Gomes I, Schneider RH, Schwanke CH. Lack of association of body composition and functionality variables with metabolic syndrome in the elderly. Metab Syndr Relat Disord. 2014;12(7):397-401. https://doi.org/10.1 089/met.2014.0012.

39. Tieland M, Trouwborst I, Clark BC. Skeletal muscle performance and ageing. J Cachexia Sarcopenia Muscle. 2018;9(1):3-19. https://doi.org/10.1002/ jcsm.12238.

40. Cruz-Jentoft AJ, Bahat G, Bauer J, Boirie Y, Bruyère O, Cederholm T, Cooper C, Landi F, Rolland Y, Sayer AA, Schneider SM, Sieber CC, Topinkova E, Vandewoude M, Visser M, Zamboni M, Writing Group for the European Working Group on Sarcopenia in Older People 2 (EWGSOP2), and the Extended Group for EWGSOP2. Sarcopenia: revised European consensus on definition and diagnosis. Age Ageing. 2019;48(4):601. https://doi.org/10.1 093/ageing/afz046.

41. Kim KM, Jang HC, Lim S. Differences among skeletal muscle mass indices derived from height-, weight-, and body mass index-adjusted models in assessing sarcopenia. The Korean J Internal Med. 2016;31(4):643-50. https:// doi.org/10.3904/kjim.2016.015.

42. Katz LD, Glickman MG, Rapoport S, Ferrannini E, DeFronzo RA. Splanchnic and peripheral disposal of oral glucose in man. Diabetes. 1983;32(7):675-9. https://doi.org/10.2337/diab.32.7.675.

43. Jans A, Konings E, Goossens GH, Bouwman FG, Moors CC, Boekschoten MV Afman LA, Müller M, Mariman EC, Blaak EE. PUFAs acutely affect triacylglycerol-derived skeletal muscle fatty acid uptake and increase postprandial insulin sensitivity. Am J Clin Nutr. 2012;95(4):825-36. https:// doi.org/10.3945/ajcn.111.028787.

44. Pedersen BK, Febbraio MA. Muscle as an endocrine organ: focus on musclederived interleukin-6. Physiol Rev. 2008;88(4):1379-406. https://doi.org/10.11 52/physrev. 90100.2007

45. Perakakis N, Triantafyllou GA, Fernández-Real JM, Huh JY, Park KH, Seufert J, Mantzoros CS. Physiology and role of irisin in glucose homeostasis. Nat Rev Endocrinol. 2017;13(6):324-37. https://doi.org/10.1038/nrendo.2016.221.

\section{Publisher's Note}

Springer Nature remains neutral with regard to jurisdictional claims in published maps and institutional affiliations.

Ready to submit your research? Choose BMC and benefit from:

- fast, convenient online submission

- thorough peer review by experienced researchers in your field

- rapid publication on acceptance

- support for research data, including large and complex data types

- gold Open Access which fosters wider collaboration and increased citations

- maximum visibility for your research: over $100 \mathrm{M}$ website views per year

At $\mathrm{BMC}$, research is always in progress.

Learn more biomedcentral.com/submissions 